\section{SPECIAL CORRESPONDENCE,}

\section{PARIS.}

The New University Law.-Dangers of Santonin Sugar Plums.The International Congress of Hydrology, Climatology, and Geology:-Administrative Mania in France.

THe Benate is about to name a Commission to examine the New University Law, which has been voted unanimously by the Lower Chamber. In the last bulletin of the Minister of Public Instruction of grants, receipts, and register of students in the French faculties during the ten years 1884 to 1895 it is stated that in 1884 a total of 14,000 students were registered in the different faculties, and in 189524,000 . In 1884 Government granted to the faculties $£ 460,000$. In ten years f I04,000 has been added, making a total of $£ 564,000$. The faculties received from students' fees ten years ago very nearly $£ 160,000$, and last year a little more than 260,000 . In 1884 each university student cost f21 18s, 4d. In consequence of the considerable afflux of pupils, the cost to the university for each student is now fII os. Iod. The French universities consider that Government does not treat them with sufficient liberality. In support of their plea the grants to the German universities are quoted; these are $f 400,000$ more than the amount granted by the French Government. No hope is entertained that by Government help the French universities will rival the German universities in organisation of laboratories, libraries, and general excellence. The project of departmental universities is by many considered a measure which will remedy this unsatisfactory condition of things. State help will not be the only resource. The General Council of each department, likewise the Municipal Council, and private generosity will contribute to swell the funds.

Dr. Gaston calls attention to the danger of allowing grocers to sell sugar plums containing santonin for curing worms. Dr. Gaston was called in to treat two children who had taken some of these dragees à vers. One, a child 3 years old, was cold, cyanosed, and insensible. Hot drinks and mustard plasters restored the infant invalid. In the second case a little girl of 4 died in a few hours, presenting all the symptoms of acute peritonitis. The previous evening the parents had given her santonin dragées. Here the influence of santonin is not so evident, but it may nevertheless be suspected.

The fourth session of the International Hydrological, Climatological, and Geological Congress will be held at Clermont-Ferraud at the end of September, 1896. In the Hydrological Section the following subjects will be studied: The dominant action and the special therapeutic influence of certain mineral waters; what is to be understood by the expression "a water cure," the part played by the water cure and that of the accessory medical treatment; the action of mineral waters on nutrition; the therapeutic influence of carbonic acid and alkaline bicarbonates on mineral waters; a special study of the legislation relative to mineral waters and the sanitary police in mineral water stations; the supply of mineral waters; sterilising and bottling mineral waters for transportation. In the Climatological Section: How to appreciate the clearness and the coloration of the sky and their sanitary influence; the prevalence of winds in regions and their influence on sanitary conditions; meteorological observations, their place in climatological study; the dust contained in the atmosphere, under what conditions it is carried in it, its influence on sanitary conditions.

The incurable mania among the French for "administration" has succeeded in rendering almost useless the magnificent gift of Mme. Furtado Heine, who placed at the disposal of the Government her Villa de Nice. This villa she intended to be utilised as a convalescent home for officers. It is capable of receiving 40 inmates. Mme. Heine has endowed it with a yearly income of 62,400 . Two hundred applications have been sent in to the War Minister. Twelve officers have entered the Villa, but have left it. It appears that the Villa falls under the jurisdiction of the service de Santé. This administration puts it on the same footing as the other military hospitals submitted to its authority, such as Amélie-les-Bains and Plombières, the same discipline is imposed. The intention of Mme. Furtado
Heine to provide ease and comfort for the inmates of the Villa is disregarded, notwithstanding the substantial pension of $£ 2,400$ yearly provided for the purpose. Furthermore a colonel pays $3 \mathrm{~s}$. 2 d., a captain $2 \mathrm{~s}$. I Id., a lieutenant $2 \mathrm{~s}$. $6 \mathrm{~d}$. a day. If one article of food is changed a small charge is made. The inmates are obliged to rise at an early hour in order to allow the servants to clean their rooms. These annoyances, added to that of being obliged to be in at a certain hour in the evening, have all but emptied the Villa de Nice.

\section{GLASGOW.}

Lord Kelvin's Jubilee.-The Roentgen Rays.-Glasgow Royal Infirmary Schaw Convalescent Home.-Chair of Midwifery in Anderson's College.-Bovine Tuberculosis.

LORD KELvin completes the fiftieth year of his tenure of the Chair of Natural Philosophy in Glasgow University in the autumn of this year. Previous to this only two professors at Glasgow have for so long occupied a chair: one was Professor of Mathematics-Robert Simson-who completed 50 years in I76I ; and the other was Dr. James Jaffrey, who held the Chair of Anatomy from I790 to 1848. The Corporation of Glasgow has associated itself with the University for the purpose of celebrating Lord Kelvin's jubilee in a fitting manner. The celebrations will occur on June 15th and 16th. Invitations are being sent to Universities and learned and scientific societies at home and abroad, asking them to participate in them.

The Roentgen rays are receiving their share of attention in Glasgow. The Physical Laboratory at the University is mucl occupied with experiments in this direction, and Dr. John Macintyre is devoting a great deal of time to the same subject. Last night (Friday, 27th) he gave a demonstration illustrating the physics, photography, and direct vision of the rays, and exhibited various forms of the cryptoscope.

The Glasgow Royal Infirmary was formally endowed with a convalescent home on Saturday last. The gift is presented by Miss Marjory Schaw in memory of her brother. The home is situated about five miles from the centre of Glasgow, at Bearsden, one of the prettiest of the suburbs of the city. Miss Schaw set aside for the purposes of the home a sum of $£ 40,000$ in 1891, and has since added $£ 7,000$, so that not only has a magnificent and fully equipped building been placed at the disposal of the managers of the infirmary, but it is endowed to the extent of $£_{15}, 000$.

Dr. John Edgar has succeeded Dr. W. L. Reid as Professor of Midwifery in Anderson's College Medical School, Dr. Reid having lately resigned the appointment.

Lately Dr. A. K. Chalmers, one of the medical officers of health, took occasion to bring the subject of tuberculosis in cattle before the Glasgow Dairymen's Association, and discussed with them the chief facts of practical importance brought out in the recent Royal Commission report. He also brought before the dairymen the legislative movement in America and France directed against the spread of bovine tuberculosis.

ERRATUM. - In the letter from our Berlin correspondent which appeared in the BRITISH MEDICAL JOURNAL of March Itth, p; 6or , col. 2 , line 9 from top his view that incubation tuberculosis and traumatic tuberculosis differ from the tuberculosis of phthisis. This view is shared by Virchow, and was expressed by him in the Berlin Medical Society.

\section{CORRESPONDENCE،}

\section{THE COUNCIL OF THE COLLEGE OF SURGEONS} AND ITS MEMBERS.

Sir,-It does not seem to me a matter of very deep regret that the Council of the College should have thrown down the gauntlet to the body corporate of Fellows and Members on the question of direct representation as they have done, nor that they should have chosen such a high and mighty mode of expressing themselves in the resolution declaring their determination to fight the matter out to the bitter end. L'etat c'est moi expresses in brief the opinion of the ruling powers at the College, and those who have followed the pro- 